\title{
Perancangan Kartu Permainan Kesenian Ondel-Ondel
}

\author{
Daniel Saarani ${ }^{1}$, Taufan Hidayatullah ${ }^{2}$ \\ ${ }^{1}$ Desain Komunikasi Visual, Fakultas Desain, Universitas Komputer Indonesia, Bandung \\ ${ }^{2}$ Magister Desain, Fakultas Pasca Sarjana, Universitas Komputer Indonesia, Bandung \\ Email: Idanielsaarani@mahasiswa.unikom.ac.id, ${ }^{2}$ taufan.hidayatullah@email.unikom.ac.id
}

\begin{abstract}
Abstrak: Kesenian budaya Betawi mempunyai berbagai jenis kesenian salah satunya kesenian Ondel-Ondel tanpa adanya tutur kata yang berada di daerah kota Jakarta. Kesenian Ondel-Ondel mengalami adanya perubahan pada Ondel-Ondel, yang dimana pada fenomena Ondel-Ondel munculnya fungsi lain yang dijadikan sebagai pengamen. Penetapan pada topik ini bertujuan menitikberatkan pada informasi kesenian Ondel-Ondel melalui media permainan card game yang didalamnya meliputi sejarah, fungsi dan esensi berdasarkan wawancara, survey, kuesioner dan sumber literatur serta melestarikan dan mempertahankan eksistensi Ondel-Ondel di zaman modern yang tidak hanya dianggap sebagai pajangan, melainkan untuk tetap aktif dalam kesenian dan pertunjukkan. Pada perancangan topik kesenian Ondel-Ondel yang ditemukan bahwa beberapa dari masyarakat kota Jakarta hanya sekedar mengetahui wujud Ondel-Ondel tapi belum mengetahui fungsi, makna dan sejarahnya, kemudian pada pemerintahan dan komunitas ataupun para pengrajin harus lebih bekerja sama untuk tetap mempertahankan eksistensi Ondel-Ondel secara kesenian dan pertunjukkan.
\end{abstract}

Kata kunci: Budaya, kesenian, Ondel-Ondel, kartu permainan.

\begin{abstract}
The art of Betawi culture has a variety of arts, one of which is Ondel-Ondel art without speech in the city area of Jakarta. Ondel-Ondel's artistry is subjected to alterations in Ondel-Ondel, which in the phenomenon of Ondel-Ondel The emergence of other functions used as a pengamen. The determination of this topic aims to emphasize the art information Ondel-Ondel through the media game card games that include the history, functions and essences based on interviews, surveys, questionnaires and literary sources and preserve and maintain the existence of Ondel-Ondel in modern times that not only regarded as a display, but to remain active in arts and performances. In the design of the art topic of Ondel-Ondel which is found that some of the people of Jakarta just know the form of Ondel-Ondel but do not know the function, meaning and history, then in the government and community or craftsmen must work together to maintain the existence of Ondel-Ondel arts and performances.
\end{abstract}

Keywords: Culture, art, Ondel-Ondel, card game. 


\section{PENDAHULUAN}

Masyarakat Betawi dikenal sebagai penduduk asli wilayah kota Jakarta yang sudah ada sebelum Jan Pieterzoon Coen membakar Jayakarta pada tahun 1619 dan mendirikan sebuah kota yang bernama Batavia atau yang sekarang dikenal sebagai kota Jakarta. Keberadaan penduduk Betawi menurut pendekatan sejarawan dan pada perancangan yang terkait, telah menduduki Jakarta sejak zaman Neoliticium sekitar pada tahun 1500 SM. Sekitar pada abad ke-17 dan ke-18 yang dimana suku Betawi ini lahir dari pencampuran pernikahan berbagai suku yang ada di Batavia. Masyarakat Betawi mempertahankan budayanya secara turun-temurun dan memiliki bahasa atau dialek yang disebut bahasa Betawi. Masyarakat Betawi secara garis historis dibagi dua kelompok yaitu Betawi Kota dan Betawi Pinggir. Betawi Pinggir yang merupakan orang Betawi yang tinggal di daerah pinggiran dan di kenal dengan nama Betawi Ora. Kemudian Betawi Kota atau Tengah adalah yang tinggal di tengah kota (Chaer, A. (2015, h27. Suku Betawi memiliki beragam jenis kesenian diantarnya Tanjidor, Gambang Kromong, Lenong dan Ondel-Ondel yang merupakan kesenian tanpa tutur kata (tanpa dialog).

Pada kesenian Ondel-Ondel nama lainnya ialah Barongan mempunyai makna Bersama-sama pada abad ke-16. Pada abad ini Ondel-Ondel dijadikan persembahan atau ibadah pada masa Sunda Kelapa berdasarkan penjelasan narasumber Bapak Supandi. Kemudian Barongan pada abad ke-19 berkembang menjadikan sebuah acara arak-arakan namun diiringi dengan seperti mantra atau do'a. Tetapi hal ini masih belum dapat dipastikan dari penjelasan narasumber. Kemudian hal ini juga pada para leluhur nenek moyang dipercayai bahwa Ondel-Ondel bertujuan untuk melindungi masyarakat Betawi dari roh-roh jahat yang membawa bencana. Kemudian pada tahun 1966-1977 Gubernur Ali Sadikin mengangkat Ondel-Ondel sebagai kesenian. Pada tahun 2014 tepatnya tanggal 17 Januari Ondel-Ondel diresmikan sebagai ikon kota Jakarta. Dalam kesenian memiliki banyak jenis bisa dilihat dengan cara penyampaiannya dengan media suara, tari, lukis, pentas drama dan patung (Koetjaningrat, 1990, h. 45).

Pada perancangan media informasi mengenai kesenian Ondel-Ondel ini pada perkembangannya memiliki temuan-temuan yang terjadi di Jakarta. pada OndelOndel fenomena yang terjadi munculnya fungsi lain dijadikan sebagai pengamen berdasarkan temuan survey lapangan secara langsung dan pada penjelasan narasumber Bapak Supandi bahwa dari pihak pemerintahan yang sekarang belum adanya tindakan lanjut untuk kesenian Ondel-Ondel ke depannya dalam mempertahankan kesenian Ondel-Ondel. Hal ini sangat disayangkan bahwa pelestarian Budaya Betawi dikhawatirkan mengalami penurunan dalam keberadaan Ondel-Ondel. Dalam kesenian Ondel-Ondel banyak pesan moral yang bisa diambil dan juga mempunyai makna-makna mendalam.

Tetapi disisi lain seperti pengrajin Ondel-Ondel juga masih ada pelanggan untuk pembuatan boneka Ondel-Ondel serta pada Gedung-gedung kesenian, pemerintahan dan beberapa rumah sakit memiliki boneka Ondel-Ondel untuk dipajang pada tiap pintu masuk. Sehingga hal ini juga memiliki dinamika pada 
pelestarian budaya pada Ondel-Ondel yang memiliki nilai, pesan moral, sakralitas dan makna. Diskursus menyingkap sebuah fenomena kebudayaan dari sudut yang berbeda dan tersembunyi (Hidayatullah, 2011).

Dalam hal ini melestarikan budaya Betawi di kota Jakarta bisa memberikan dampak positif. Dampak yang bisa di dapatkan adalah memberikan informasi tentang Ondel-Ondel, mulai dari sisi sejarah, fungsi, esensi Ondel-ondel dan ada penambahan makna-makna pada Ondel-Ondel dari motif,warna, dan aksesoris yang dipakai oleh boneka Ondel-Ondel serta adanya hiburan untuk para masyarakat Jakarta. Hal ini dilakukan untuk melestarikan kebudayaan Betawi dengan menitikberatkan pada menginformasikan kembali esensi dari Ondel-Ondel yang saat ini mulai menurunnya eksistensi dan menaikkan potensi-potensi kesenian budaya Betawi.

\section{METODE}

Pada perancangan informasi yang disajikan agar dapat diterima pada khalayak sasaran. Maka pada perancangan ini melakukan metode atau strategi yang diterapkan pada perancangan informasi. Menerapkan perancangan informasi mengenai informasi kesenian Ondel-Ondel. Perancangan konsep dan dikemas bertujuan menarik perhatian khalayak sasaran. Pada konsep perancangan media informasi ini merupakan media permainan card game dengan adanya tema kesenian Ondel-Ondel kepada khalayak sasaran remaja pertengahan.

\section{Metode Analisa}

Pada target khalayak sasaran ini ialah masyarakat kota Jakarta dengan usia 15-18 tahun (remaja pertengahan) dengan jenis kelamin laki-laki dan perempuan, berpendidikan SMA dan Universitas dengan pekerjaan pelajar atau mahasiswa/i dengan status sosial menengah bawah dan menengah atas. Untuk kelompok usia ini perkembangan baik keunikan pertumbuhan secara fisik, psikologis maupun sosial yang dimana memasuki masa yang penuh strorm and stress atau bisa disebut masa pubertas (Wulandari, 2014).

Pada letak geografi pada kota Jakarta karena masih adanya penyampaian informasi kesenian Ondel-Ondel belum banyak yang mengetahui secara sejarah, fungsi dan makna berdasarkan temuan-temuan secara langsung dan wawancara. Perancangan ini berdasarkan consumer insight yang dituju memiliki kecenderungan terhadap daya tarik pada permainan dan daya tarik pada pengetahuan baru pada hal-hal tertentu. Menurut Jahja (2011, h. 231), remaja secara aktif membangun dunia kognitif para remaja yang dimana telah mampu menyaring informasi dengan pola pikir secara efisien pada pengetahuan baru yang telah dialami dan diamati.

Berdasarkan consumer journey aktivitas-aktivitas yang dilakukan oleh khalayak luas lebih sering menggunakan media handphone untuk kebutuhan pribadi baik sosial media, komunikasi dan mencari informasi dalam keseharian. 


\section{Strategi Komunikasi}

Penerapan strategi komunikasi pada perancangan ini meggunakan media permainan card game karena bertujuan menginformaskan kembali tentang kesenian OndelOndel yang ditargetkan kepada khalayak sasaran, diharapkan pesan-pesan atau informasi untuk khalayak sasaran bisa dapat di terima dan memahami.

\section{Tujuan dan Pendekatan Komunikasi}

Tujuan dari perancangan ini menginformasikan kembali tentan kesenian OndelOndel dengan harapan berdampak positif kepada khalayak sasaran untuk mempertahankan kebudayaan dan pelestarian serta meningkatkan kepedulian pada fenomena yang terjadi. Pendekatan yang relevan pada remaja pertengahan dan menambah pengetahuan baru dalam hal kesenian Ondel-Ondel.

Materi Pesan yang disampaikan pada perancangan ini mengenai keunikan dari kesenian Ondel-Ondel dari sejarah, fungsi dan esensi melalui media permainan yang menghibur dan melibatkan lebih dari satu orang yang dimana terdapat nilainilai dari pesan yang disampaikan pada perancangan media informasi ini. Penetapan pada gaya bahasa perancangan ini merupakan penerapan dalam mengekspresikan pikiran dan perasaan dengan bahasa yang mempunyai keunikan dan sesuai pada inspirasi, kepribadian dan perilaku untuk pengarangnya pada penyampaian gaya bahasa dengan menimbulkan efek tertentu. Sehingga gaya bahasa berhubungan dengan erat pada ideologi dan latar sosiokultural pengarang atau pembuatnya (Al-Ma'ruf, 2009, h. 6).

Gaya bahasa majas personifikasi yang dimana majas ini gaya bahasa yang mencerminkan kiasan pada benda-benda mati seolah-olah memiliki sifat kemanusiaan (Waridah, 2014, h.12). Majas personifikasi ini digunakan pada bagian visual dan copywriting pada perancangan media informasi tersebut. Pendekatan verbal menggunakan bahasa Indonesia formal dengan penggunaan bahasa Indonesia yang baik dan benar. Kemudian adanya penambahan dialek Betawi pada bagian copywriting untuk menambahkan kesan Betawi.

\section{Mandatory}

Perancangan pada media informasi melalui media permainan ditetapkan pada yang mempunyai wewenang dalam hal mendistribusikan serta publikasi media informasi. Mandatory yang ditetapkan pada perancangan ini ialah DISPARBUD DKI JAKARTA. penetapan mandatory ini lembaga tersebut mempunyai wewenang dalam publikasi, informasi dan dokumentasi yang keterkaitan budaya atau pariwisata. 


\section{jakarta}

Gambar 1. Logo DISPARBUD DKI Jakarta

Sumber: http://jakarta-tourism.go.id/2017/download/search

\section{Strategi Kreatif dan Media}

Copywriting merupakan dimana memaksimalkan komunikasi dengan tujuan promosi kepada target audiens (Albright, 2013). Copywriting pada media permainan ini menambahkan dialek Betawi diterapkan pada judul "Ondel-Ondel Jakarte Pesona Kite", alasan menetapkan judul ini adalah menetapkan secara garis historis karena pada media informasi ini mengutamakan seperti sejarah, fungsi dan esensi pada kesenian Ondel-Ondel.

Untuk tagline yang ditetapkan ialah "Kembang Kesenian" yang diambil dari kosakata "berkembang" yang memberikan makna perkembangan dari sesuatu hal yang menjadi besar, luas dan dari jumlah banyak, menurut arti dari kata kbbi dari kosakata "berkembang". Headline yang ditetapkan pada copywriting ialah "Kudu Eksis dan Berkembang" penjelasan pada headline ini dari kata "Eksis" mewakili bagaimana perkembangan kesenian Ondel-Ondel ditengah-tengah perkembangan zaman yang sudah canggih dengan diwilayah pusat perkotaan, sebagai tantangan untuk tetap aktif dalam hal kesenian dan pertunjukkan Ondel-Ondel. Perancangan media informasi ini pertama kali yang dibuat adalah sketsa digital pada karakter Ondel Ondel dengan gaya ilustrasi cartoon.
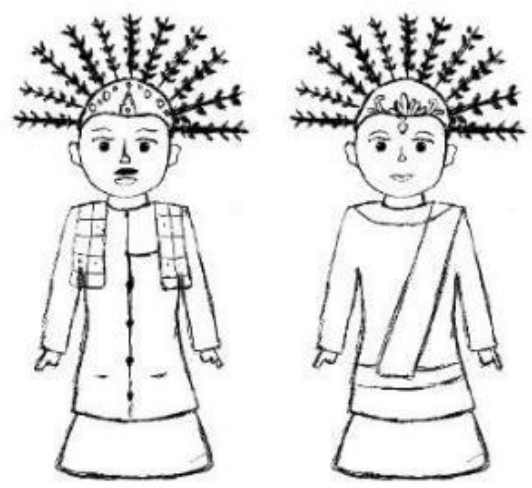

Gambar 2. Perancangan Visual Karakter Ondel-Ondel Sumber: Dokumen Pribadi, 2020 


\section{HASIL DAN PEMBAHASAN}

Perancangan pembuatan media informasi mengenai kesenian Ondel-Ondel melalui media permainan card game. Beberapa permainan kartu diantaranya Kopi Dash, Uno, Linimasa, serta kartu Yu Gi Oh! dan Pokemon. Dalam pembuatan permainan memiliki beberapa komponen konsep visual yang harus di perhatikan seperti tata letak, tipografi, warna, dan ilustrasi. Komponen inilah yang menentukan media permainan menjadi menarik.

\section{Format Desain}

Format desain pada card game ini hampir mirip seperti kartu uno. Pada media permainan card game ini pada media utamanya dengan ukuran $11 \times 7 \mathrm{~cm}$ yang dimainkan oleh 2 sampai pemain. Pengukuran tersebut karena adanya sebuah narasi teks yang terdapat pada card game.

\section{Tata Letak}

Tata letak atau layout merupakan sebuah alat bantu pada penerapan elemen pada media tertentu bertujuan menyampaikan sebuah konsep dan pesan yang munculkan (Rustan, 2008, h. 67). Tata letak pada permainan kartu ini didalamnya terdapat visual karakter ataupun objek yang diaplikasikan pada kartu tersebut dan disertai dua tipe kartu yaitu jawaban dan pertanyaan. Pada tata letak card game ini menggunakan tata letak simetris dengan melihat aspek komposisi yang mewakili kesan seimbang, konservatif dan formal (Kertamukti, 2017).
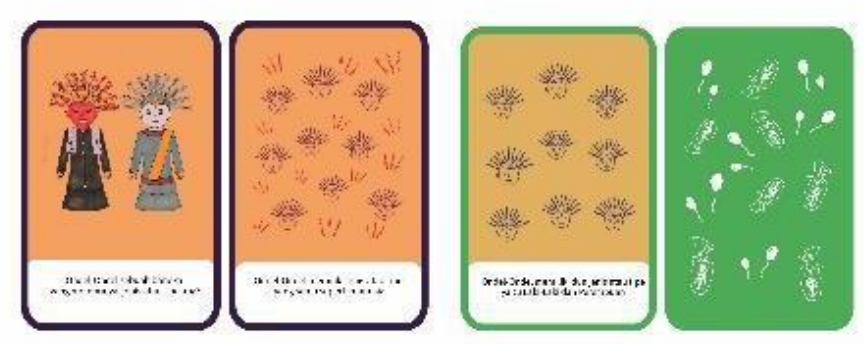

Gambar 3. Tata Letak Card Game

Sumber: Dokumen Pribadi, 2020

\section{Tipografi}

Tipografi menghubungkan komunikasi dan informasi yang tidak berdiri sendiri secara ekslusif (Rustan, 2013, h. 4). Dalam perancangan media informasi dengan media utamanya media permainan, judul yang nantinya dimunculkan menggunakan tipografi dari font Modak desainer huruf ini Sarang Kulkarni dan Maithili Shingre Pada font ini adalah jenisnya sans-serif dengan memiliki karakter kontras, lucu dan tidak kaku. Penetapan font ini adalah memiliki kesan 
yang sama pada gaya ilustrasi yang dimunculkan. Font ini memiliki kekuatan dalam bentuk dengan tebal dan kontras. Hal ini membantu agar nantinya para pembaca tidak kesusahan dalam pembacaan judul media permainan. Font-family ini ialah regular dengan tipe yang hampir terlihat seperti bold yang bisa di dapatkan secara gratis di website google font.

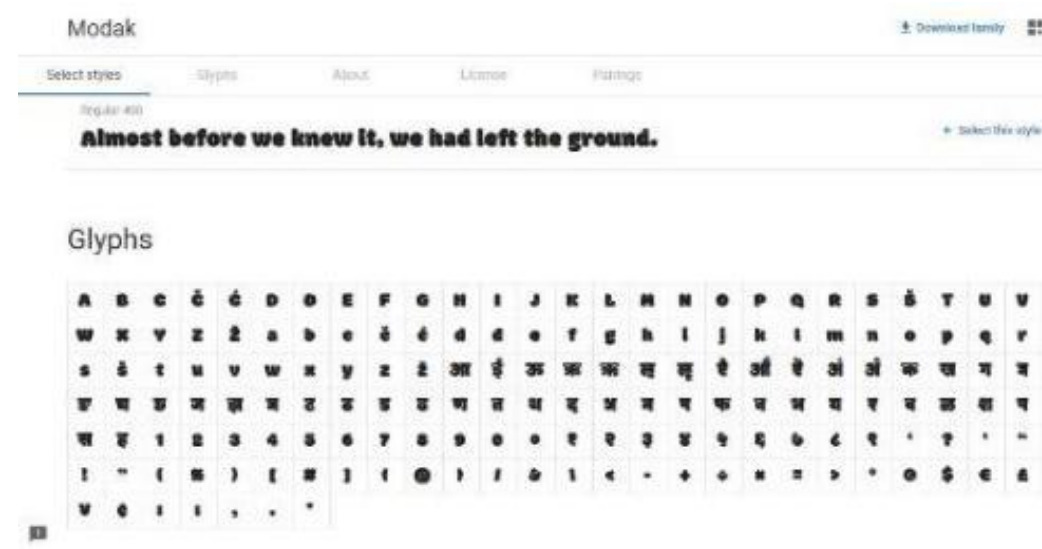

Gambar 4. Screenshot Tampilan font Modak

Sumber: https://fonts.google.com/specimen/Modak\#standard-styles (2020)

Kemudian pada pemilihan font untuk teks yang nantinya akan dimunculkan pada kartunya yang berisikan seperti informasi, jawaban, penjelasan, pertanyaan yang terkait pada media permainan tersebut dengan memilih font Noto Sans JP yang dibuat oleh google yang dilisensikan pada 26 Februari 2007. Font ini bisa didapatkan pada website Google font. Penetapan pada font ini adalah memiliki keterbacaan yang jelas dan baik pada bodytext yang nantinya akan diaplikasikan pada media permainan ini. Jenis font ini adalah sans-serif dan font family yang dipilih adalah regular.

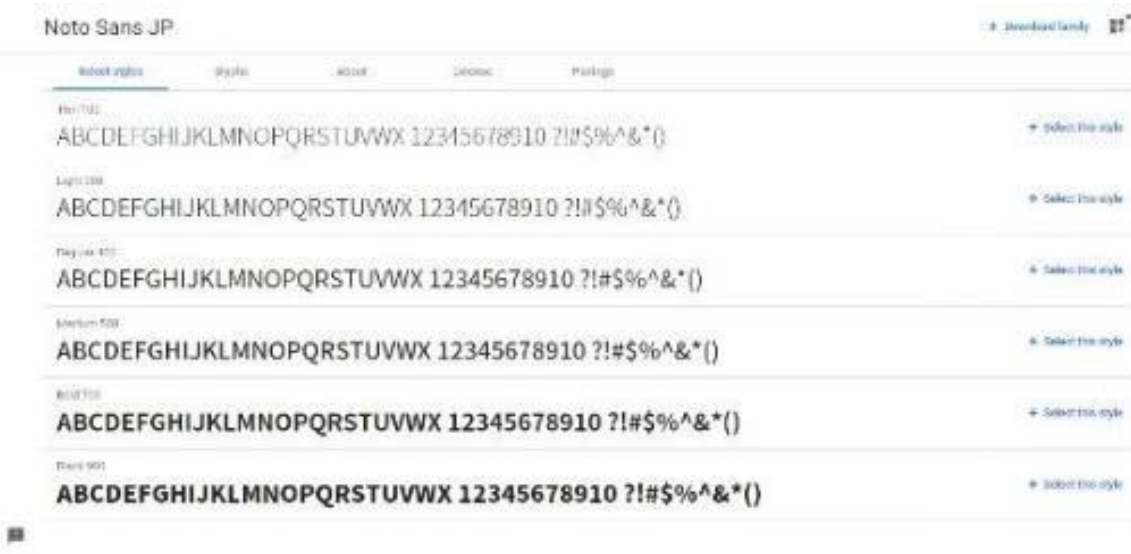

Gambar 5. Screenshot Tampilan Font Noto Sans JP Sumber: https://fonts.google.com/specimen/Noto+Sans+JP?category (2020) 


\section{Ilustrasi}

Ilustrasi merupakan sebuah media penyampaian dengan penggambaran dengan fungsi menjelaskan pesan yang ingin disampaikannya (Maharsi, 2016, h.2). Ilustrasi yang dipakai pada media permainan ini adalah menggunakan ilustrasi cartoon Indonesia dan Amerika dengan penyederhanaan dalam bentuk ilustrasinya. Untuk pewarnaan dalam ilustrasi ini menggunakan watercolour secara digital, pemilihan teknik warna tersebut karena perpaduan warna yang dikeluarkan pada watercolour ini secara fleksibel dan memberikan perbedaan pada media permainan lainnya.

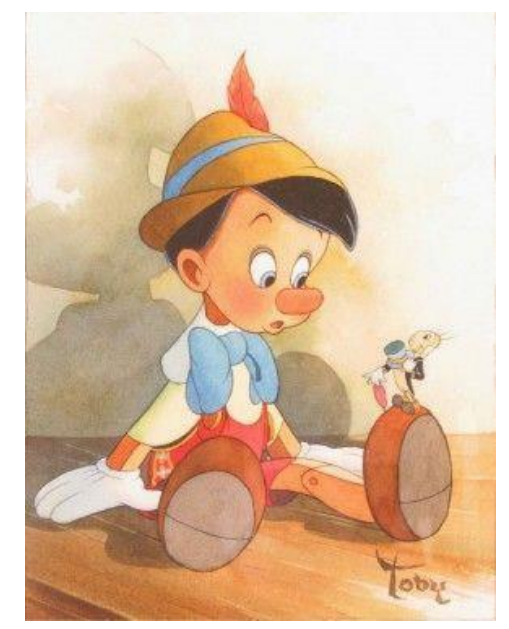

Gambar 6. Referensi Pengaplikasian Watercolour Digital

Sumber: https://i.pinimg.com/564x/6b/24/b1/6b24b1f2fc9ecc34aa48a8735bab327f.jpg (2020)

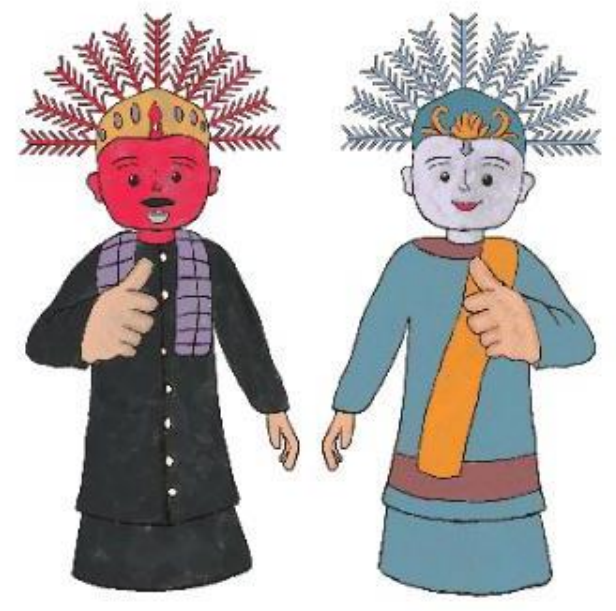

Gambar 7. Ilustrasi Ondel-Ondel

Sumber: Dokumen Pribadi, 2020 


\section{Warna}

Pada penerapan warna yang dimana menambah estetika elemen-elemen yang terdapat pada suatu objek, secara subjektif ataupun objektif (Meilani, 2013). Pada media permainan ini beberapa penetapan warna pada visual karakter utamanya Ondel-Ondel dan warna kartu bagian belakang pada tipe dua warna yang berbeda dengan bertujuan sebagai perbedaan atau estetika dari objek maupun subjek yang dimunculkan nantinya pada media permainan ini.

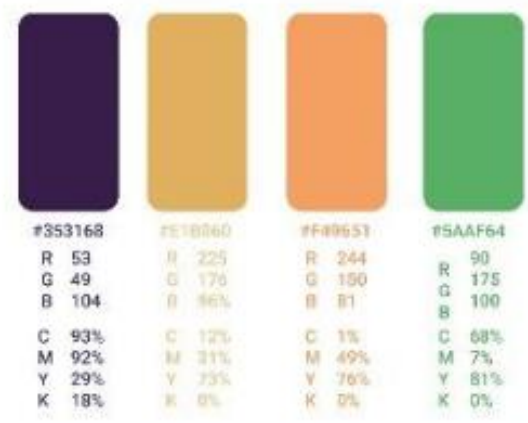

Gambar 8. Warna Dua Tipe Kartu Sumber: Dokumen Pribadi, 2020

\section{Media Utama}

Media utama dari perancangan ini adalah media informasi melalui media permainan card game. Dalam media utama ini melibatkan 2 sampai 4 pemain untuk memainkan permainan card game ini. Pada desain card game ini melibatkan dua jenis tipe kartu terdiri dari kartu pertanyaan dan jawaban yang akan mencocokan kartu-kartu tersebut dengan pertanyaan yang ada pada kartu pertanyaan. Ukuran kartu ini ialah $11 \mathrm{~cm} \times 7 \mathrm{~cm}$ diproduksi dengan cetak offset untuk kebutuhan fullcolour dengan bahan art paper 260gr
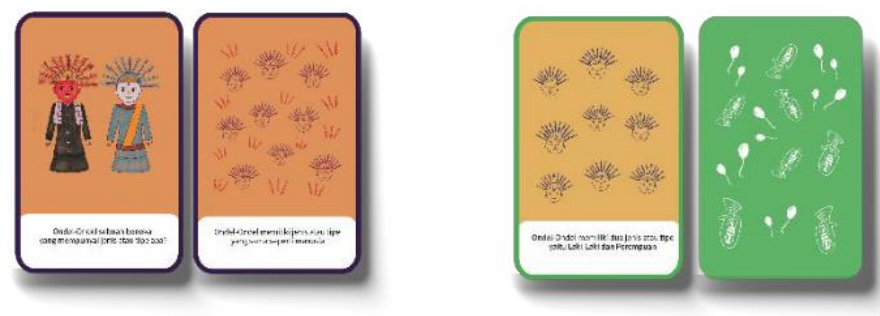

Gambar 9. Kartu Media Permainan Sumber: Dokumen Pribadi, 2020 
Pada desain kemasan card game ini berfungsi sebagai wadah pada card game berserta informasi teknis permainannya. Produksi yang dipakai cetak offset secara fullcolour dengan bahan art paper $260 \mathrm{gr}$. Ukuran kemasan ini $16 \mathrm{~cm} \times 10 \mathrm{~cm}$.

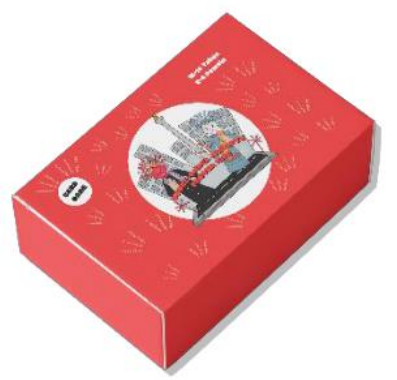

Gambar 10. Desain Kemasan Card Game

Sumber: Dokumen Pribadi, 2020

\section{Media Pendukung}

Media pendukung bertujuan promosi untuk menarik para khalayak sasaran serta penyampaian informasi dan pesan. Pada media pendukung mini $x$-banner ini bertujuan dengan promosi pada perilisan media permainan yang ditunjukkan pada event tertentu untuk mempromosikan media permainan card game. Ukuran $\mathrm{x}$-banner ini 30x40 cm. Dengan produksi teknik digital print secara fullcolour dengan bahan syntethic. Mini x-banner juga lebih efisien terhadap penempatan display.

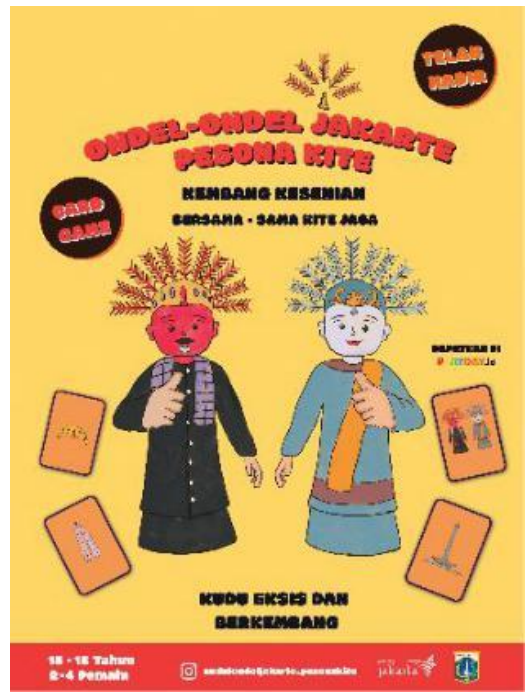

Gambar 11. Desain Mini X-Banner Sumber: Dokumen Pribadi, 2020 
Pada media pendukung poster bertujuan mempromosikan media permainan card game berseta informasi terkait perilisan card game pada event tertentu. Proses produksinya menggunakan produksi cetak offset secara fullcolour dengan ukuran 29,7 x $42.0 \mathrm{~cm}$ dengan bahan art paper 260gr dengan finishing laminasi doff.

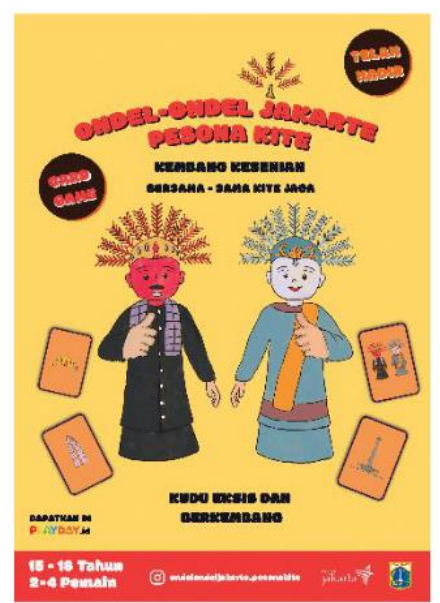

Gambar 12. Desain Mini Poster Sumber: Dokumen Pribadi, 2020

Pada media pendukung Kaos yaitu bertujuan mempromosikan media permainan card game dengan menarik ketertarikan pada sasaran khalayak. Proses produksinya menggunakan produksi sablon polyflex secara fullcolour dengan finishing pada mesin heat press. Bahan kaos pada merchandise ini cotton combed 30s. Dengan pengaplikasian ilustrasinya pada bagian kaos depan dan belakang.
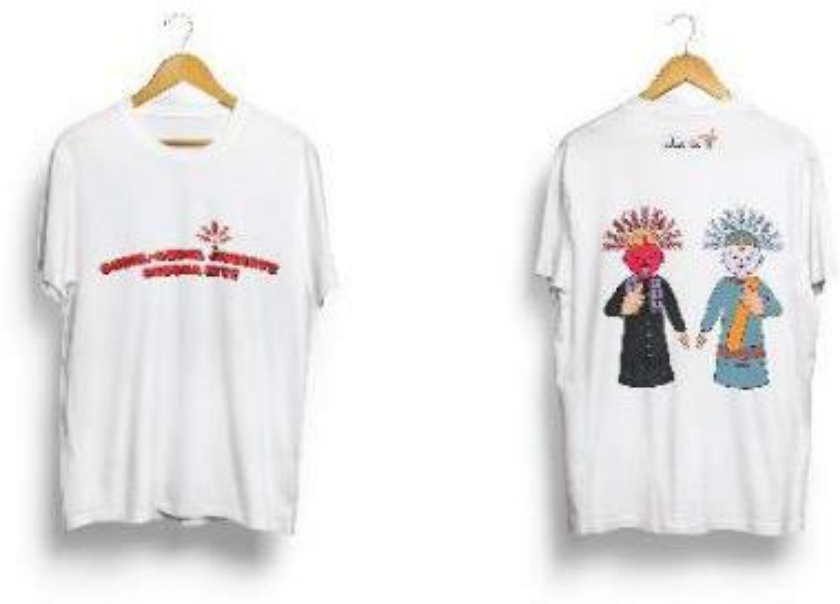

Gambar 13. Merchandise Kaos Sumber: Dokumen Pribadi, 2020 
Pada merchandise totebag bertujuan pada untuk menarik perhatian sasaran khalayak serta berfungsi juga sebagai penyimpanan barang-barang seperti alat tulis, buku, tumbler dan barang lainnya. Proses produksi yang dipakai pada merchandise totebag ini dengan sablon polyflex dan finishing menggunakan mesin heat press.

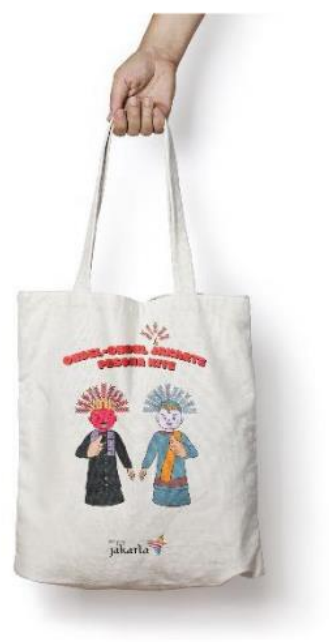

Gambar 14. Merchandise Tote bag

Sumber: Dokumen Pribadi, 2020

Dengan adanya media pendukung sticker yang bertujuan sebagai pemanfaatan dalam penjualanan card game pada paket merchandise dan card game. pada proses produksi sticker ini menggunakan cetak offset secara fullcolour dengan bahan sticker chromo dan ukuran desain $6 \mathrm{~cm} \times 6 \mathrm{~cm}$.

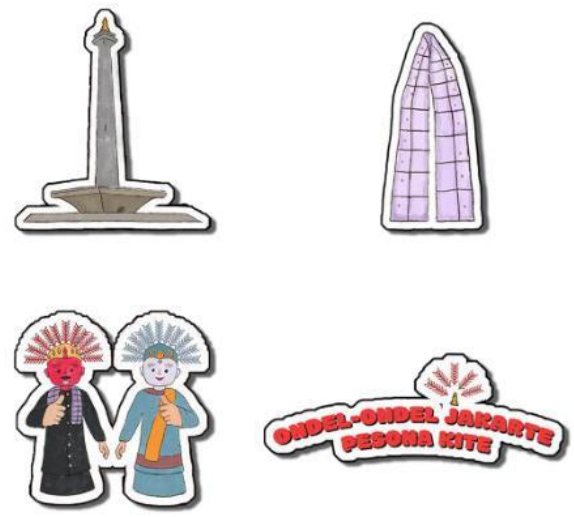

Gambar 14. Merchandise Sticker Sumber: Dokumen Pribadi, 2020 
Pada merchandise gantungan kunci yang berfungsi sebagai souvenir dan ditambahkan pada paket merchandise dalam pembelian card game. Teknis produksi ini menggunakan cetak digital print dan finishing laminasi doff.
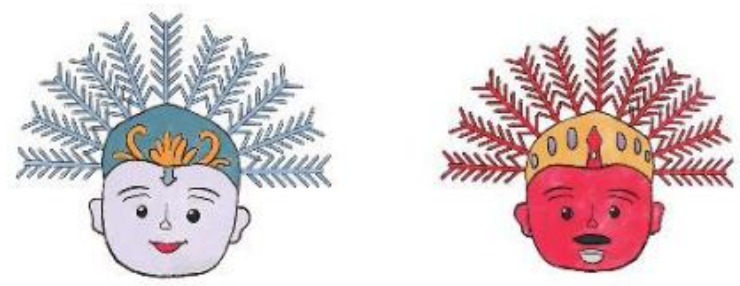

Gambar 16. Desain Gantungan Kunci Sumber: Dokumen Pribadi, 2020

Pada merchandise tumbler ini dengan bagian promosi pada perilisan card game dengan adanya tambahan bonus merchandise tumbler. Pada teknis produksinya menggunakan teknik cetak offset bahan art paper $120 \mathrm{gr}$ secara fullcolour. Tipe tumbler yang dipakai jenis plastik yang dimana sangat memudahkan untuk meletakkan desain pada tipe tumbler ini

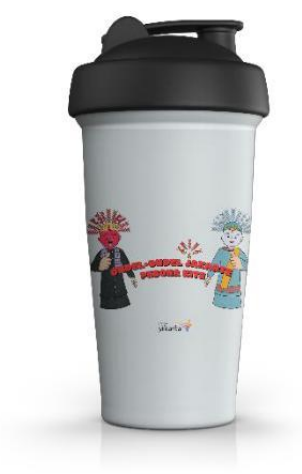

Gambar 17. Merchandise Tumbler

Sumber: Dokumen Pribadi, 2020

\section{KESIMPULAN}

Kesimpulan pada perancangan media informasi ini dimana harus tetap mempertahankan budaya atau pelestarian baik dari sejarah, fungsi, makna dan seni pertunjukkannya. Menumbuhkan rasa kepedulian terhadap fenomena-fenomena yang terjadi pada Ondel-Ondel. Kemudian pada perancangan ini masih berpotensi pada pengembangan visual ilustrasi dan narasi yang sesuai target khalayak yang diperancangkan. Kesenian budaya dalam pelestariannya yang harus tetap dijaga, hal ini mempunyai dampak yang baik untuk para pelesarian budaya secara kompak 
dan tetap aktif pada kesenian dan pertunjukkan. Kepada pihak-pihak yang berwenang agar memberikan gagasan baru terhadap kesenian Ondel-Ondel untuk kedepannya. Pada perancangan ini berdasarkan dari data-data masyarakat lingkup daerah Jakarta, sumber literatur buku, sehingga masih adanya beberapa yang belum memenuhi kriteria yang baik. Pada perancangan media permainan gaya ilustrasi harus lebih mendalam pada aspek kultur yang sesuai pada target khalayak. Karena memasukkan aspek kultur bisa menyesuaikan pada media permainan selanjutnya.

\section{DAFTAR PUSTAKA}

Al-Ma'ruf, A. I. (2009). Stilistika: Teori, Metode, dan Aplikasi Pengkajian Estetika Bahasa.

Albrighton, T. (2013). The abc of copywriting. United Kingdom: ABC Business Communication Ltd.

Chaer, A. (2015). Betawi Tempo Doeloe Menelusuri Sejarah Kebudayaan Betawi. Depok: Masup Jakarta.

Hidayatullah, T. (2011). DISKURSUS JENDER DALAM "KEBUDAYAAN ITU BERKELAMIN - KOMIK TENTANG ARAHMAIANI". VISUALITA, 3(1). https://doi.org/10.33375/vslt.v3i1.1094

Jahja, Y. (2011). Psikologi perkembangan. Kencana.

Koentjaraningrat, P. I. A., \& Pembangunan, M. (2009). Pengantar Ilmu Antropologi Cet. 9; Jakarta: PT. Rineka Cipta.

Kertamukti, R. (2017). Komunikasi Visual Iklan Cetak Rokok di Indonesia Kurun Waktu 1950-2000. Jurnal ASPIKOM, 1(1), 91-108.

Rustan, S. (2008). Layout Dasar dan Penerapannya. Gramedia Pustaka Utama.

Rustan, S. (2013). Font And Tipografi. Gramedia Pustaka Utama.

Waridah, E. (2014). Kumpulan Majas, Pantun, dan Peribahasa Plus Kesusastraan Indonesia. Ruang Kata.Gunadi, A. (2005). Basic Theory for Wildlife Photographers. Oxford: Focal Press.

Wulandari, A. (2014). Karakteristik pertumbuhan perkembangan remaja dan implikasinya terhadap masalah kesehatan dan keperawatannya. Jurnal Keperawatan Anak, 2(1), $39-43$. 